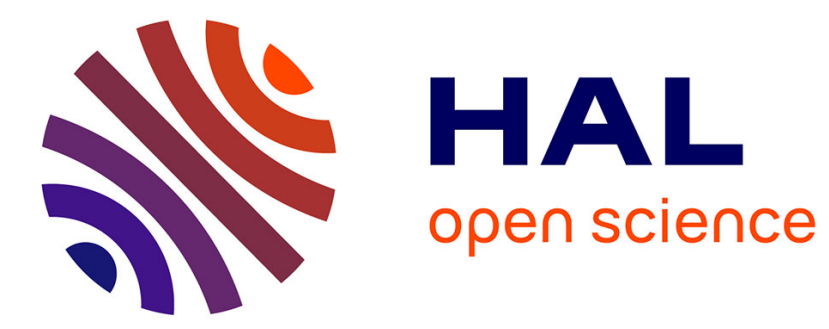

\title{
X-ray analysis by electron spectroscopy
}

J. Cazaux

\section{- To cite this version:}

J. Cazaux. X-ray analysis by electron spectroscopy. Journal de Physique Lettres, 1977, 38 (23), pp.473-476. 10.1051/jphyslet:019770038023047300 . jpa-00231423

\section{HAL Id: jpa-00231423 https://hal.science/jpa-00231423}

Submitted on 1 Jan 1977

HAL is a multi-disciplinary open access archive for the deposit and dissemination of scientific research documents, whether they are published or not. The documents may come from teaching and research institutions in France or abroad, or from public or private research centers.
L'archive ouverte pluridisciplinaire HAL, est destinée au dépôt et à la diffusion de documents scientifiques de niveau recherche, publiés ou non, émanant des établissements d'enseignement et de recherche français ou étrangers, des laboratoires publics ou privés. 


\author{
Classification \\ Physics Abstracts \\ $07.85-78.70 \mathrm{E}-79.60-82.80$
}

\title{
X-RAY ANALYSIS BY ELECTRON SPECTROSCOPY (*)
}

\author{
J. CAZAUX \\ Groupe de Spectroscopie Electronique, \\ Faculté des Sciences, 51062 Reims, France
}

\begin{abstract}
Résumé. - En utilisant l'effet photoélectronique $X$ et à l'aide d'un dispositif spécial, il est possible de mesurer les raies d'émission $X$ avec une résolution en énergie de $0,1 \mathrm{eV}-1 \mathrm{eV}$ et une résolution spatiale de 1 micron; les éléments légers peuvent aussi être détectés et les applications possibles en microanalyse $\mathrm{X}$ sont indiquées.
\end{abstract}

Abstract. - By the use of a special arrangement and with the help of the X-ray photoelectric effect, it is possible to measure characteristic X-ray emission lines with an energy resolution of $0.1 \mathrm{eV}-1 \mathrm{eV}$ and a spatial resolution of one micron. Light elements can also be detected and applications in electron probe analysis are pointed out.

1. Introduction. - In ESCA (or XPS) the unknown binding energy $E_{\mathrm{B}}$ of electrons in a given sample illuminated by a known X-ray radiation $h v$ are deduced from the measurement of the kinetic energies $E_{\mathrm{K}}$ of the corresponding photoelectrons by using the basic equation $E_{\mathrm{B}}=h v-E_{\mathrm{K}}$; by reversal of this equation, the first main idea of this paper is to deduce the intensity and photon energy distribution of an X-ray source from measurements of the kinetic energy and intensity of the photoelectrons emitted by a known element (converter) : figure 1 shows an example of the expected photoelectron spectrum of a thin carbon film (converter) illuminated by $\mathrm{X}$-rays emitted by an aluminiummagnesium anode. For further applications in electron probe microanalysis and $\mathrm{X}$-ray distribution imaging

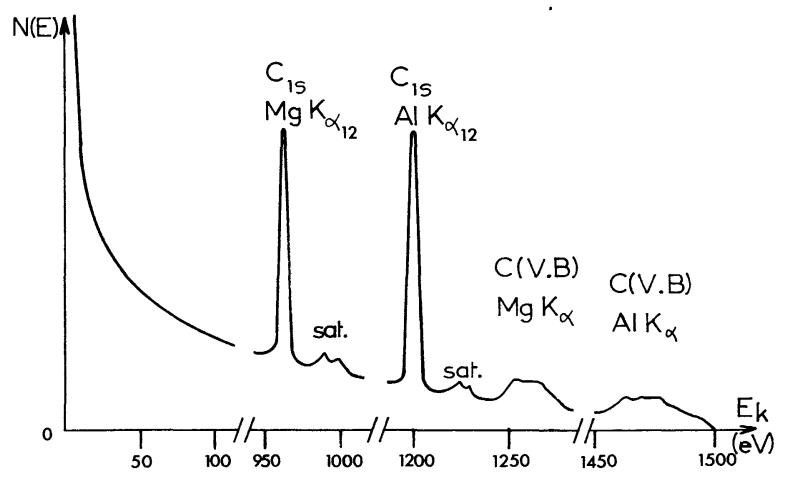

FIG. 1. - Expected photoelectron spectrum obtained with a carbon converter irradiated by a $\mathrm{Mg}-\mathrm{Al}$ alloy anode.

$\left(^{*}\right)$ Patent under application. instead of the classical arrangement used currently in photoelectron spectrometers, we suggest that the converter should be attached as a thin film below the anode being studied, which should be in the form of a thick sheet $(1-5 \mu)$ to improve the corresponding photoelectron intensity. A similar arrangement, which was first proposed by the author for photoelectron $\mathrm{X}$-ray microanalysis and microscopy $[1,2]$ has been successfully used by Hovland [3, 4] showing that, according to the theoretical predictions $[1,2]$, it is possible to reduce the analysed area down to the micron range and to obtain a photoelectronic image in the scanning mode [4].

2. Principle and expected performances. 2.1 Principle. - The principle is shown in figure 2 : an electron beam is focused on the upper part of the anode which is in the form of a thick foil (1); this creates characteristic X-rays, which disperse in all directions, some passing through the foil reaching the converter (2) at the opposite side to the incident beam where photoelectrons are created, and analysed by an electron spectrometer. The electron beam is used in a scanning mode to generate a two dimensional X-ray distribution image or in a stationary position for recording the electron probe analysis spectra.

2.2 THE CONVERTER. - The converter material will have a high subshell photoionization crosssection $\left(\sigma_{n 1}\right)$, the corresponding photoelectron line being narrow ( $\Delta E<1 \mathrm{eV}$ for energy resolution) and having a low binding energy (to detect $K_{\alpha}$ radiations of the light elements because $E_{\mathrm{B}}<h_{v}$ ) : the intense gold doublet $4 \mathrm{f}_{5 / 2} 4 \mathrm{f}_{7 / 2}\left(E_{\mathrm{B}}=87 \mathrm{eV}\right.$ and $\left.83 \mathrm{eV}\right)$ partially 


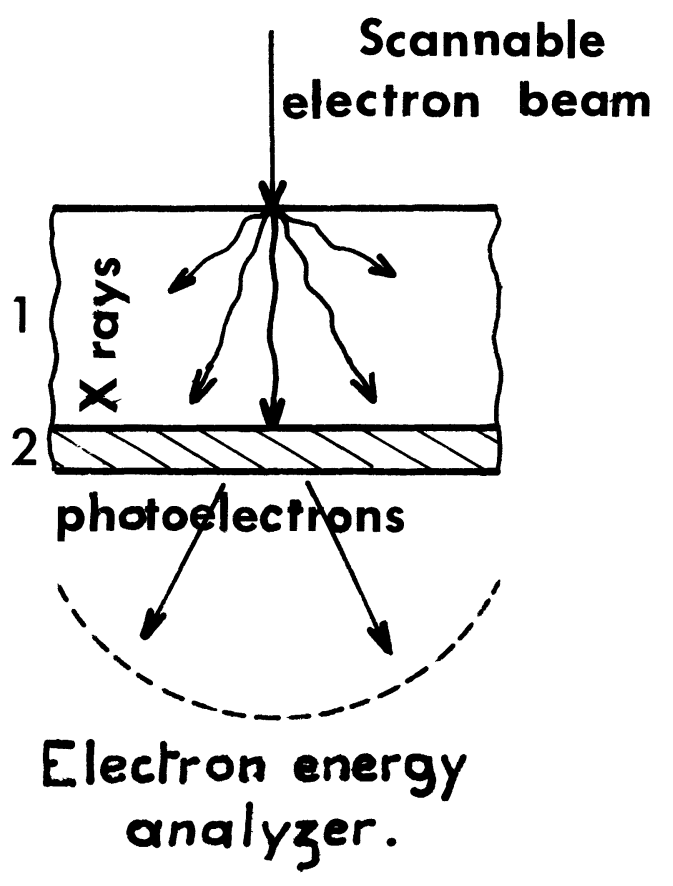

FIG. 2. - Proposed arrangement : $a$ ) for X-ray photoelectron microscopy and spectroscopy (I) : (1) aluminium anode (2) specimen ; $b$ ) for XAES : (1) specimen (2) converter.

fulfils these requirements and furthermore gold is a good conductor, chemically insensitive and easy to prepare as a thin film of uniform thickness. Nevertheless, in order to prevent confusion between several photoelectron lines excited by different X-ray radiations, amorphous carbon or boron (with only. one narrow inner line (1s) + one broad band (valence band) see Fig. 1) can also be chosen, keeping in mind that the fundamental disadvantage of carbon is its incapability to detect carbon (and $\mathrm{B}, \mathrm{Be}, \mathrm{Li}$ ) !! The useful thickness of the converter corresponds to the escape depth $\lambda_{\mathrm{e}}$ of the photoelectrons (so that a converter thickness of about 5-10 nm will generally be adopted) and its quantum efficiency $\eta_{\mathrm{pe}}$ (photons $\mathrm{X} \stackrel{\eta_{\mathrm{pQ}}}{\longrightarrow}$ photoelectrons) is given by

$$
\eta_{\mathrm{pe}} \simeq \rho . \sigma_{\mathrm{nl}} \lambda_{\mathrm{e}} \simeq \mu_{\mathrm{x}} \lambda_{\mathrm{e}}
$$

where $\mu_{\mathrm{x}}$ represents the absorption coefficient of the $\mathrm{X}$-ray radiation in the converter material. The value $\eta_{\mathrm{pe}} \simeq 10^{-3}$, which roughly corresponds to a gold film illuminated by an $\mathrm{AlK}_{\alpha}$ radiation (1), can be adopted as a mean value.

2.3 ENERGY RESOLUTION AND TRANSPARENCY OF THE ELECTRON SPECTROMETER. - The value of $10^{-4}$ can easily be reached for the resolving power $\Delta E / E$ of the electron spectrometer, so $\mathrm{K}_{\alpha} \mathrm{X}$-ray lines up to zinc $(Z=30)$ and $\mathrm{L}$ or $\mathrm{M}$ lines for heavier elements can be detected with a $0.1 \mathrm{eV}-1 \mathrm{eV}$ energy resolution $\Delta E$ and an acceptance solid angle $\Delta \Omega$ greater than $10^{-1}$ sterad. for a cylindrical mirror analyser.
2.4 EXPECTED INTENSITY AND RESULTING EFFICIENCY. - To improve the expected intensity $N(\theta, \Delta \theta)$ of a photoelectron line measured at the output of the electron spectrometer and the corresponding total quantum efficiency

$$
\eta_{\mathrm{T}}=\frac{N(\theta, \Delta \theta)}{I_{0}}
$$

we now have to optimize the X-ray intensity $Q$ produced in the anode material and the corresponding quantum efficiency $\eta_{\mathrm{x}}\left(\eta_{\mathrm{x}}=Q / I_{0}\right)$. Apart from the choice of the best anode thickness $t$ - and the self absorption coefficient $(E)$ of X-rays in the anode this problem resembles the electron microprobe problem first resolved by Castaing [5] : following Castaing's procedure step by step the value of $10^{-3}$ can be reached for $\eta_{\mathrm{x}}$ in an aluminium anode with a thickness which roughly corresponds to the effective spot size $z_{\mathrm{m}}-$ see exp. 24 in [5]. Finally applying the following expressions given by the author for X-ray photoelectron microanalysis, we obtain (expression 11 in (1) which also holds here) :

$$
\begin{aligned}
N(\theta, \Delta \theta) & =\left(\frac{Q}{2}\right)(E)\left(\eta_{\mathrm{pe}}\right)\left(\frac{\Delta \Omega}{2 \Pi}\right), \\
\eta_{\mathrm{T}} & =\frac{1}{2}\left(\eta_{\mathrm{x}}\right)(E)\left(\eta_{\mathrm{pe}}\right)\left(\frac{\Delta \Omega}{2 \Pi}\right) .
\end{aligned}
$$

We can expect to have (see table $I$ in [1]) $E \simeq 1$, $\eta_{\mathrm{T}} \simeq 10^{-8}, N(\theta, \Delta \theta) \simeq 10^{6} \mathrm{cps} / \mathrm{s}$ for a gold converter on an aluminium anode,

$$
\eta_{\mathrm{T}} \simeq 10^{-8}, \quad N(\theta, \Delta \theta) \simeq 10^{4} \mathrm{cps} / \mathrm{s}
$$

for the same converter on a heavier anode (N.B. : Table III in [1]). These estimates are in moderately good agreement with Hovland's preliminary experimental result (4)

$$
\begin{gathered}
\left(\eta_{\mathrm{T}} \simeq 2 \times 10^{-10}, \quad N(\theta, \Delta \theta) \simeq 48.000 \mathrm{cps} / \mathrm{s},\right. \\
S / B \simeq 8.5)
\end{gathered}
$$

obtained with the $\mathrm{O}_{1}$ line (?) on an $\mathrm{Al}$ anode free of deposited converter.

2.5 Comparison With EDS AND WDS TeChNIQUES IN X-RAY MICROANALYSIS. - In the analysis of medium-range elements $(10<Z<30)$, the following points may be of interest :

- With the proposed technique (X-ray analysis by electron spectrometry : XAES), the expected intensity will be of the same order of magnitude as in Energy Dispersive Spectrometry (and greater than in Wavelength Dispersive Spectrometry) because, despite the fact that the quantum efficiency of the converter and the acceptance angle of the analyzer are reduced, the converter covers a very large solid angle $(2 \Pi$ sterad.).

- The energy resolution in XAES $(<1 \mathrm{eV})$ is better than in EDS $(150 \mathrm{eV})$ or in WDS $(5 \mathrm{eV})(6)$. 
TABLE I

\begin{tabular}{|c|c|c|c|c|c|c|c|}
\hline & $\begin{array}{l}\text { Energy } \\
\text { resolution } \\
\end{array}$ & $\begin{array}{c}\text { Spatial } \\
\text { resolution }\end{array}$ & $\begin{array}{c}\text { Intensity } \\
\mathrm{cps} / \mathrm{s}\end{array}$ & $S / N$ & $\begin{array}{l}\text { Quanti- } \\
\text { tative ana- } \\
\text { lysis (pre- } \\
\text { cision) }\end{array}$ & $\begin{array}{c}\text { Detection } \\
\text { of light } \\
\text { elements } \\
\end{array}$ & $\begin{array}{l}\text { Ease of } \\
\text { operation }\end{array}$ \\
\hline $\begin{array}{c}\text { XAES } \\
\text { (proposed } \\
\text { technique) }\end{array}$ & $<1 \mathrm{eV}$ & $1 \mu \mathrm{m}$ & $10^{5}-10^{6}$ & $\sim 10$ & $10-20 \%$ & yes easily & $\begin{array}{c}\text { very } \\
\text { very despite }\end{array}$ \\
\hline $\begin{array}{l}\text { EDS (6) } \\
\text { WDS (6) }\end{array}$ & $\begin{array}{r}150 \mathrm{eV} \\
5 \mathrm{eV}\end{array}$ & $\begin{array}{l}1 \mu \mathrm{m} \\
1 \mu \mathrm{m}\end{array}$ & $\begin{array}{l}10^{5}-10^{6} \\
10^{4}-10^{5}\end{array}$ & $\begin{array}{l}20-50 \\
1000\end{array}$ & $\begin{array}{l}1 \% \\
1 \%\end{array}$ & $\begin{array}{c}\text { no } \\
\text { difficult }\end{array}$ & $\begin{array}{l}\text { liquid } N^{2} \\
\text { difficult }\end{array}$ \\
\hline
\end{tabular}

- In the X-ray imaging mode, the spatial resolution will be the same for all these techniques because the volume irradiated by incoming electrons is the same.

- The peak to background ratio will be poorer in XAES than in the other techniques because, to the background created by the white radiation we have to add the electronic background due to incident electrons slowing down through the anode and, above all, the important background caused by inelastic scattering of the photoelectrons in the converter.

- If it is reasonable to compare the intensity of a photoelectron line given by the sample with the intensity of the same line obtained on a pure element of the same thickness and covered by the same converter, it seems that the expected precision obtained in XAES will be poorer than the precision obtained by counting the photon fluxes directly, even if very refined correction programs are used; in this way, XAES will be a very useful technique for identifying quickly the elements of a given sample with, perhaps, their chemical shift.

- Detection of light elements : electron probe microanalysis is difficult to perform for elements of low atomic numbers $(Z)$ because $: i)$ the fraction of inner shell excitations that give rise to an X-ray quantum rather than an Auger electron falls rapidly with $Z$, ii) the detection efficiency is poor in WDS (due to X-ray absorption by the windows) and impossible in EDS (due to the lack of energy resolution) (6). The use of XAES cannot overcome the physical reason $i$ but its quantum efficiency increases with the wavelength (in the converter $\mu_{\mathrm{x}}$ increases when $\lambda$ increases) and a decided interest of this technique is its ability to detect the technologically important light elements of $\mathrm{Be}, \mathrm{B}, \mathrm{C}, \mathrm{O}$ and $\mathrm{N}$ (for both metallurgical and biological applications).

- Ease of operation and multipurpose apparatus : XAES technique (image and analysis), being an electron spectroscopy technique, can be easily developed in the ultra high vacuum environment of an Auger electron apparatus. By adding an Auger gun inside the electron analyzer (C.M.A. type) and by inverting the sample, it is possible to combine the Auger analysis with the X-ray analysis, in succession, on the same specimen to obtain its surface and its bulk compositions : an arrangement which is highly desirable in a great number of cases [7]; furthermore, the X-ray radiography, ESCA image and analysis can also be performed in a very versatile apparatus [8]. The ease of operation in the XAES technique is better than in the WDS technique (where X-ray spectrometry needs the use of different bent crystals and complicated linkages between crystal and detector) and can be compared with the EDS technique : if the practical efficiency of an E.D. spectrometer is increased by its simultaneous use of the X-ray spectrum instead of the sequential processing used in XAES, other processing facilities are the same and XAES does not require the use of liquid nitrogen.

The above comparisons are summarized in the table I.

3. Conclusion. - We suggest the use of electron spectroscopy for the measurement of X-ray photon energies; applied to electron probe microanalysis this new technique allows all elements $(Z>3)$ to be detected with the same intensity and processing facilities as in the EDS technique and an energy resolution $(0.1 \mathrm{eV})$ better than in the WDS technique. This technique, which can be combined in the same apparatus, with other electron spectrometry and imaging techniques (Auger, Esca [1] etc.), would seem to be very useful in thin film and surface physics. From a more general point of view, we see that with the original arrangement proposed by the author, a characteristic X-ray source, with the same intensity as synchrotron radiation (giving $10^{5}$ photoelectrons per second in each case $\left(^{1}\right)$ but with an X-ray photon density $10^{4}$ times larger, is easy to obtain in a simple laboratory : many other applications of this technique will undoubtedly appear in the future [8].

Acknowledgments. - It is a pleasure to thank Dr. Hovland for helpful discussions.

( $\left.{ }^{1}\right)$ Lecante J., C.E.N. Saclay, B.P. no 2, Gif-sur-Yvette, France, Private communication. 


\section{References}

[1] Cazaux, J., Revue Phys. Appl. 10 (1975) 263.

[2] Cazaux, J., J. Micros. Spectros. Elect. 1 (1976) 73.

[3] Hovland, C. T., Appl. Phys. Lett. 30 (1977) 274.

[4] Hovland, C. T., Proc. 7th Int. Cong. Vac. and 3rd Int. Conf. Solid Surfaces Vienna 1977, p. 2363.

[5] Castaing, R., Adv. Electron. and Electron Phys. 13 (1960) 317.
[6] Easterling, K. E., Proc. 6th Europ. Conf. Elec. Micros. 1 (1976) 52. D. G. Brandon Edit. TAL Int. Pub. Co.

[7] KIRSCHNER, J., Electron. Spectroscopy for Surface Analysis, IBACH Ed. (Springer Verlag) 1977, 103.

[8] Cazaux, J., J. Phys. E : Scien. Instr. (to be published). 